\title{
2 I I MRI of coronary vessel wall injury in a swine model of coronary intervention using an eletrostatically stabilized VSOP nanoparticle
} Christian von Bary ${ }^{1}$, Anne Preissel ${ }^{2}$, Susanne Wagner ${ }^{3}$, Marcus R Makowski ${ }^{4}$, Alexandra Keithahn ${ }^{4}$, Elmar Spuentrup ${ }^{5}$, Albert Schoemig1, Simon Robinson ${ }^{6}$, Joel Lazewatsky ${ }^{6}$, Markus Schwaiger ${ }^{4}$, Joerg Hausleiter ${ }^{1}$, Matthias Taupitz ${ }^{3}$ and René $M$ Botnar*4

Address: ${ }^{1}$ Cardiology Division, Technische Universität München, Munich, Germany, ${ }^{2}$ Center for Preclinical Research, Technische Universität München, Munich, Germany, ${ }^{3}$ Diagnostic Radiology, Charite, Berlin, Germany, ${ }^{4}$ Nuclear Medicine, Technische Universität München, Munich, Germany, ${ }^{5}$ Diagnostic Radiology, Cologne University, Cologne, Germany and ${ }^{6}$ Bristol-Myers Squibb Medical Imaging, North Billerica, MA, USA

* Corresponding author

from I th Annual SCMR Scientific Sessions

Los Angeles, CA, USA. I-3 February 2008

Published: 22 October 2008

Journal of Cardiovascular Magnetic Resonance 2008, I0(Suppl I):A72 doi:10.1 I86/I532-429X-10-SI-A72

This abstract is available from: http://jcmr-online.com/content/I0/SI/A72

(C) 2008 von Bary et al; licensee BioMed Central Ltd.

\section{Introduction}

Atherosclerosis is an inflammatory disease of the vessel wall with unstable lesions being associated with the presence of inflammatory cells, smooth muscle cell apoptosis, and the accumulation of LDL. Dextran coated superparamagnetic iron oxide (SPIO) nanoparticles ( $20 \mathrm{~nm}$ ) have been shown to allow for imaging of plaque resident macrophages approximately $>24 \mathrm{~h}$ post intravenous injection. Citrate coated very small iron oxide (VSOP) nanoparticles $(\sim 7 \mathrm{~nm})$ have been found useful for steady state aortic and coronary MR angiography (MRA) but also have been shown to accumulate in advanced aortic lesions in a rabbit model of atherosclerosis.

\section{Purpose}

In this study we wanted to test the hypothesis whether the combined use of an extracellular matrix specific Gd-based contrast agent (BMS753951) together with a VSOP nanoparticle would allow the exclusive visualization of the pathologically altered coronary vessel wall in an animal model of coronary intervention.

\section{Methods}

Placement of MR-lucent prototype stents was performed in the proximal left coronary artery (LAD) of two female domestic swine ( $30 \mathrm{~kg}$ ). Following a one week normal diet, coronary MRA and delayed enhancement vessel wall imaging was performed using a $1.5 \mathrm{~T}$ Philips Achieva MR scanner. Immediately before the imaging session, animals were injected with $0.1 \mathrm{mmol} / \mathrm{kg}$ BMS753951, an elastinbinding low molecular weight Gd-based contrast agent (Bristol Myers Squibb, Billerica, MA). After localization of the heart, coronary MRA was performed using a steady state free precession imaging sequence. 30 minutes post BMS753951 injection, delayed enhancement coronary wall imaging was performed with spatial resolution, slice thickness and image orientation maintained using an inversion recovery (IR) fast gradient echo technique. Subsequently, $60 \mu \mathrm{mol} / \mathrm{kg}$ VSOP (Ferropharm, Teltow, Germany) was injected and IR coronary MRA was performed with the inversion delay adjusted to minimize signal from myocardium. 45 minutes post VSOP administration, delayed enhancement vessel wall imaging was repeated with the inversion time adjusted to minimize signal from arterial blood. Immediately after the MRI session, animals were euthanized and hearts were harvested for histological examination. 


\section{Results}

Strong enhancement of the stented left coronary artery and no apparent enhancement of the non-injured right coronary artery (RCA) was observed in both animals 30 minutes post administration of BMS753951 (Figure 1b) suggestive for ECM formation in the stented coronary artery segment. In addition, strong enhancement was also present in the aorta and pulmonary arteries (Figure 1b) due to the high elastin content in those vessels. Immediately post injection of VSOP, free-breathing inversion recovery MRA yielded good visualization of the blood pool in large vessels and also good visualization of the stented LAD but with attenuated luminal signal when compared to the large and coronary control vessels (Figure 1c). In addition, a black rim artifact delineating the stented LAD was observed (Figure 1c) while no such effect was seen in the aorta and pulmonary artery nor in the coronary control vessel suggestive for VSOP uptake in the injured vessel wall (increased T2* effect of bound VSOP). This finding was confirmed by a delayed enhancement scan with the inversion time adjusted for blood signal nulling, which demonstrated ECM enhancement in the aortic and pulmonary vessel wall but disappearance of enhancement in the LAD vessel wall (Figure 1b vs. 1d).

\section{Conclusion}

We demonstrate the exclusive visualization of VSOP nanoparticles in the injured coronary vessel as a black rim artifact on coronary MRA. In addition, with the combined use of a matrix specific contrast agent, focal uptake of VSOP nanoparticles in the injured coronary vessel wall could be confirmed as displacement of the gadolinium signal seen after BMS753951 injection. In conclusion, VSOP nanoparticles have been shown to be useful for the detection pathological changes in the coronary vessel wall

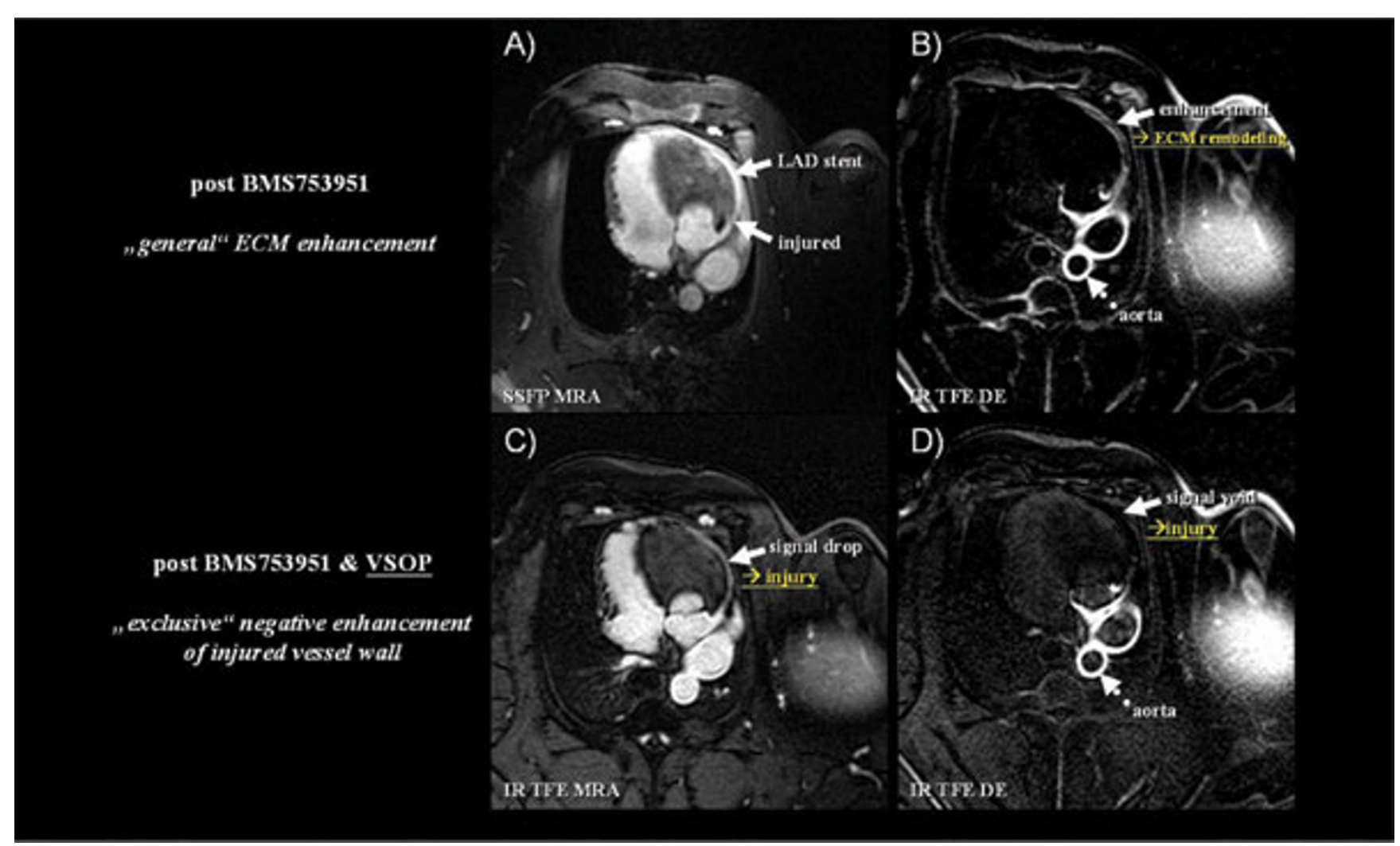

Figure I

We demonstrate the combined use of a matrix specific Gd-based contrast agent (BMS75395I) together with an iron oxide nanoparticle for exclusive visualization of the pathologically altered coronary vessel wall. (A) Coronary angiogram of stented and balloon injured left coronary artery. Note that there are no artifacts from the bare metal stent. (B) TI weighted inversion recovery delayed enhancement coronary vessel wall scan post BMS75395I injection demonstrating extracellular matrix formation one week post stent placement and injury. (C) Coronary MRA post VSOP injection demonstrating a strong TI effect of the large vessels but an attenuated blood signal in the LAD suggestive for VSOP accumulation in the injured vessel wall (increased T2* effect of bound VSOP). (D) Delayed enhancement coronary vessel wall scan post BMS75395 I and VSOP injection demonstrating displacement of the BMS75395I signal in the LAD due to VSOP accumulation in the injured vessel wall. 
and potentially may be useful for the detection unstable lesions.

Publish with Biomed Central and every scientist can read your work free of charge

"BioMed Central will be the most significant development for disseminating the results of biomedical research in our lifetime. " Sir Paul Nurse, Cancer Research UK

Your research papers will be:

- available free of charge to the entire biomedical community

- peer reviewed and published immediately upon acceptance

- cited in PubMed and archived on PubMed Central

- yours - you keep the copyright

Submit your manuscript here:

http://www.biomedcentral.com/info/publishing_adv.asp 